Discussion Papers in

Economics and Econometrics

\begin{tabular}{||l||}
\hline LIMITING POLITICAL DISCRETION AND \\
INTERNATIONAL ENVIRONMENTAL \\
POLICY COORDINATION WITH \\
ACTIVE LOBBYING \\
Surjinder Johal \\
and \\
Alistair UIph \\
No. 0212 \\
\hline
\end{tabular}

This paper is available on our website http://www/soton.ac.uk/ econweb/dp/dp02.html 


\title{
LIMITING POLITICAL DISCRETION AND INTERNATIONAL ENVIRONMENTAL POLICY COORDINATION WITH ACTIVE \\ LOBBYING
}

\author{
SURJINDER JOHAL \\ and \\ ALISTAIR ULPH \\ (University of Southampton)
}

Revised Version

August 2002

Paper presented at conference "The International Dimension of Environmental Policy", Acquafredda di Maratea, Italy, 6-11 October 2001. We are grateful to Cees Withagen and other participants for comments. 


\begin{abstract}
We address two concerns: trade liberalisation may lead to a race-to-the bottom in environmental standards; supra-national agencies, who might overcome this, may be captured by special interest groups. This raises two sets of choices: whether to set environmental policy at the national or supranational level, and whether to limit political discretion by agencies. In Johal and Ulph (2001a) we showed that policy should always be set at the supra-national level, whether or not political discretion was limited, and that it would never pay to limit political discretion at the supra-national level unless it was also limited at the national level.

In that paper there were exogenous probabilities of agencies being captured by one group or another. In this paper the probabilities of capture depend on the lobbying efforts of interest groups. We show that the results of Johal and Ulph (2001a) are robust to the introduction of active lobbying.
\end{abstract}

Key words: strategic environmental policy, international policy coordination, supra-national agencies, special interest groups, lobbying, limiting political discretion, constitutional choices.

JEL Classification: D72, F02, F12, F18, Q28

Address for Correspondence: Professor Alistair Ulph, Department of Economics, University of Southampton, Southampton, SO17 1BJ, UK. e-mail: amu@ soton.ac.uk 


\section{Introduction}

The anti-globalisation movement has raised two concerns about the alleged impact of globalisation on the environment. The first is that liberalisation of trade and capital flows encourages a "race-tothe-bottom" in environmental standards ${ }^{1}$ as independent nation states compete to attract footloose plants, especially those of multinational companies ${ }^{2}$. Assuming this concern was substantiated, this would lead naturally to a call to coordinate national environmental policies to overcome wasteful policy competition, perhaps through some supra-national agency such as WTO or, a putative World Environment Organisation (WEO). But this raises the second concern. It is claimed that that, in comparison to national agencies, supra-national agencies may be less well informed about environmental issues in nation sates, and, more importantly, that they are less democratically accountable and are more likely to be captured by the interests of multinational companies and the countries of the developed world.

To limit the political influence of special interest groups it is sometimes argued that it is necessary to limit the discretion of agencies by mandating them to adopt simple measures, such as international harmonisation of environmental policies. Economists usually argue against such policies on the grounds of inefficiency, for if nation states differ in terms of their endowment of environmental resources or their preferences for a clean environment, then efficiency requires that these differences be reflected in the environmental standards they set, whether cooperatively or noncooperatively. However, if, as is likely to be the case, information about such differences is not public knowledge, then it may be difficult to tell whether the claim by a nation state to be allowed to set laxer environmental standards is based on a real difference in, say, preferences for a clean environment, or the result of special interest groups pressing for weaker standards. So policies such as harmonisation, which would be inefficient if one assumes welfare-maximising governments, may be justifiable if they limit the scope for political influence by special interest groups.

\footnotetext{
${ }^{1}$ Without the emotive language of 'race-to-the-bottom' we are concerned with a situation where nation states acting independently would set weaker environmental standards than if the acted cooperatively. This need not imply that there are no environmental standards at all. Moreover, such a situation, sometimes called 'environmental dumping' can arise even if, as we shall assume, plants are immobile for the usual rent-shifting arguments. Of course it is well known that a necessary, but by no means sufficient, condition for environmental dumping to be plausible is that markets for international trade are imperfectly competitive.

${ }^{2}$ In this paper we deal only with local environmental problems, not transboundary pollution, where an additional set of issues arises. In Johal and Ulph (2001c) we extend the analysis of Johal and Ulph (2001b) to include transboundary pollution, and show that it leaves the results broadly unaffected. So we believe that the main results of this paper would go through with transboundary pollution.
} 
The concern about a race-to-the bottom in environmental standards can be criticised as having weak theoretical and empirical support ${ }^{3}$, but we shall suppose that it has substance and address the implications of the second concern for the setting of environmental policy. This paper extends the analysis of two recent papers we have written on this topic. In Johal and Ulph (2001a) we address directly the question of whether the need for international coordination of environmental policies of nation states to overcome damaging policy competition requires harmonisation of policies to limit political influence. Borrowing the language of fiscal federalism, we suppose that environmental policy can be set either by (nation) states, or by a federal government (or supra-national agency). If policy is set by states they will engage in wasteful policy competition. To capture information asymmetries, we suppose that only when a state government comes to power does it learn the true value of environmental damage costs in that state. In particular this information is not available to either voters or to the federal government. Whether policy is set at the state or federal level, this asymmetry of information will affect how policy is set. To capture the impact of special interest groups we suppose that there are two special interest groups - environmentalists and industrialists who (respectively) put too high or low a weight on environmental damages, and that there are elections to choose governments at both state and federal level. However the governments that are elected act not to maximise social welfare, but to further the interests of whichever one of the two interest groups got them elected.

Prior to elections taking place, and state governments learning their true damage costs, the people in the two states have to make two, independent, constitutional choices. The first is whether to have policy set at the state or federal level. The second is whether, in the language of Boyer and Laffont (1999), to have 'social pooling' or 'political discretion'. Political discretion means simply that policy will be set by the appropriate governments (state or federal depending on the first constitutional choice) acting in the interests of whichever group elected them, but recognising that state governments will know the true value of damage costs in their own state. Social pooling restricts government behaviour by requiring the appropriate governments (state or federal) to implement environmental policies which maximise social welfare but using the expected value of damage costs in each state, which is the only information about damage costs available at the time these constitutional choices are made. Since it is assumed that ex ante both states have the same 
expected damage costs, social pooling implies harmonisation. Thus, relative to social pooling, political discretion gains by allowing policies to be fine-tuned to reflect the actual damage costs prevailing in the states, but loses because governments act to benefit only part of society, not all of society. The people in the two states make the two constitutional choices based on expected social welfare (taking expectations over which types of governments will be elected and which level of damage costs states might have).

Johal and Ulph (2001a) proved three results: (i) it always pays to set policy at the federal rather than state level; (ii) whether policy is set at the state or federal level, social pooling will be preferred to political discretion when there is a relatively large difference between the preferences of different interest groups and a relatively small difference between the potential damage costs states might have; (iii) it is never the case that social pooling would be preferred to political discretion if policy is set at the federal level, but political discretion would be preferred at the if policy is set at the state level. What this means is that the need to set policy at the federal level to overcome policy competition could not be used to justify harmonisation of environmental policies if such policies had not already been harmonised (albeit at a laxer level) when policy was set at the state level.

Now in Johal and Ulph (2001a) there is no active lobbying behaviour by special interest groups in the sense that in any election the probability of electing a government which favours a particular interest group is given exogenously. Johal and Ulph (2001b) uses much of the same analysis as Johal and Ulph (2001a) but allows for active lobbying in the sense that special interest groups can now influence the probability of electing a government that will act in their interests by undertaking expensive lobbying costs. Moreover, by varying the costs of lobbying for different groups in different elections, we captured a range of asymmetries in the political process, for example allowing industrial groups to have more influence than environmental groups if policy is set at the federal level, allowing interest groups in one state ('the North') to have more influence on policy at the federal level than interest groups in the other state ('the South'). Now in this set-up, expending lobbying effort only makes sense if there is political discretion (for with social pooling governments are mandated to implement the same policy no matter which type of government is elected). Therefore in Johal and Ulph (2001b) we assumed there would be political discretion and considered only one constitutional choice: whether policy should be set at state or federal level. We showed

\footnotetext{
${ }^{3}$ See recent surveys by Ulph (2000) and Rauscher (2001) for further discussion of the theoretical and empirical
} 
that no matter what the costs of lobbying might be and what the pattern of asymmetries might be, it was always better to have policy set at the federal level. So, at least within the context of the model we employed, the benefits of eliminating wasteful policy competition outweigh whatever flaws one might think the democratic process has at the both state and federal levels.

In this paper we extend the analysis of Johal and Ulph (2001a), in particular the constitutional choice between social pooling and political discretion, to allow for the active lobbying behaviour modelled in Johal and Ulph (2001b). We show that the results of Johal and Ulph (2001a) are broadly robust to the introduction of active lobbying. By this we mean that while there are now parameter values for which it would pay states to choose social pooling if policy was set at the federal level, but to choose political discretion of policy was set at the state level, these cases are relatively rare (less than $1 \%$ of all parameter values we searched) and in these cases states are almost indifferent between social pooling and political discretion. Thus it remains the case that there are no parameter values we have found for which states would have a significant preference for social pooling at the federal level and a significant preference for political discretion at the state level.

literature. 


\section{The Model}

\subsection{The Economic Setting}

We consider a partial equilibrium model of an industry with two identical firms each located in a different state, denoted $i=1,2$. These two states form a federation. The two firms produce a good, which is sold outside the two states. Firm $i$ has total revenue and cost functions: $R\left(x_{i}, x_{j}\right), C\left(x_{i}\right)$ respectively, with standard properties. The production of the good causes emissions of a pollutant. These emissions can be abated but only at a cost. By appropriate choice of units, emissions by firm $i$ are: $x_{i}$ ? $a_{i}$ where $a_{i}$ is its abatement level; total abatement costs are the strictly convex function $A\left(a_{i}\right)$. The only instrument available to control pollution by each firm is an emission limit, denoted $e_{i}$. Firm $i$ takes as given its emission limit and the output of the other firm and chooses its own output (Cournot competition) and abatement to maximise profits, net of abatement costs: ? $\left(x_{i}, x_{j}, e_{i}\right) ? R\left(x_{i}, x_{j}\right) ? C\left(x_{i}\right) ? A\left(x_{i} ? e_{i}\right)$. Assuming that both emission limits bite, the resulting equilibrium profit function for firm $i$ is denoted $?\left(e_{i}, e_{j}\right)$.

Pollution damage in each state is caused only by emissions in the state (local pollution). The damage cost function in state $i$ is denoted ${ }_{i} D\left(e_{i}\right)$ where ${ }_{i}$ is a parameter and $D$ is a strictly convex function. Welfare in state $i$ is given by

$$
W\left(e_{i}, e_{j}, ?_{i}\right) ? ?\left(e_{i}, e_{j}\right) ? ?{ }_{i} D\left(e_{i}\right) .
$$

To capture asymmetries of information between state and federal level, we suppose that the damage cost parameter, ${ }_{i}$, in each state becomes known only to the state government once it is in power ${ }^{4}$ To keep things simple, we suppose that in state $i=1,2, ?_{i}$ can take one of only two values, $?_{L}$ and $?_{H}, \quad ?_{L} ? ?_{H}$, with probabilities $p$ and 1- $p$ respectively, independent of what happens to damages in the other state. Note that this implies that, ex ante, both states are identical. We denote the expected value of damage costs by $? ? p ?_{L} ?(1 ? p){ }_{H}$.

\footnotetext{
${ }^{4}$ In some cases it may be inappropriate to assume that a federal government is less well informed than a state government about damage costs even if pollution is local. However even if that were true, there remains the issue of whether the information could be made verifiable in court. If not then the federal government will still need to design its environmental policy to be self-enforcing. This may change the formulation of the problem but not we believe the basic results of this paper. We are grateful to Joe Swierbinski for this point.
} 


\subsection{The Political Setting}

In each country there is an environmental lobby group and an industrial lobby group; we denote the environmental lobby groups in states 1 and 2 by $g=1,2$, respectively, and the industrial lobby groups in states 1 and 2 by $g=3,4$, respectively. The two types of lobby group are distinguished by the importance they attach to environmental damage, represented by a parameter in the utility function ???which can take two values. Environmentalists attach weight to environmental damage $?_{g} ? ?$ ?? ?? ????g = 1,2 whilst industrialists attach weight $?_{g} ? ?{ }^{\prime}{ }_{L} ? ? ? ? ? ? g=3,4$. Thus the utility of group $g$ in state $i$ is given by

$$
U\left(e_{i}, e_{j}, ?_{i}, ?_{g}\right) ? ?\left(e_{i}, e_{j}\right) ? ?_{g}{ }_{i} D\left(e_{i}\right) .
$$

To relate these preferences to the welfare function we think of each state being composed only of environmentalists or industrialists in almost equal numbers ${ }^{5}$, so that in the absence of lobbying there is a probability 0.5 that the median voter is an environmentalist. We assume that $0.5\left(?_{L} ? ?_{H}\right)=1$, so that the state welfare function is simply the sum of the utilities of all individuals.

Elections are held to select the policy makers in both states and at the federal level and electoral competition takes place between two parties that are representatives of the interests of the lobby groups. Although we refer to governments and elections at state and federal level, we have in mind that the 'federal government' may refer more generally to some supra-national agency such as WTO or the putative WEO, and 'elections' may refer to some process of capture of the agency by special interest groups, where the capture process is uncertain and depends on the lobbying efforts of different interest groups in the same way as we describe for elections. We assume that, once selected, the policy makers choose policies to maximise the utility of the interest group they represent, and so will be biased towards greater or less environmental protection than represented in the welfare function. ${ }^{6}$. Thus, state government $i$ will set its policy to maximise its "utility function"

$$
U\left(e_{i}, e_{j}, ?_{i}, ?_{i}\right) ? ?\left(e_{i}, e_{j}\right) ? ?_{i} ?_{i} D\left(e_{i}\right)
$$

\footnotetext{
${ }^{5}$ We could add other groups of voters into this model with similar form of prefe rences whose weights on environmental damages were on average 1 , but who play an entirely passive role, never being median voters or members of a lobby group.

${ }^{6}$ Having a government in power, which acts solely in the interests of the group that it represents, corresponds to what Roemer (1999) calls the "militant" view of how special interest governments behave.
} 
where once again $?_{i}$ ?can be either high or low depending on whether the government of state $i$ is environmentally or industrially biased. Similarly, a federal government will set policy using its utility function

$$
U_{F}\left(e_{1}, e_{2}, ?_{1}, ?_{2}, ?_{F}\right) ? ?\left(e_{1}, e_{2}\right) ? ?\left(e_{2}, e_{1}\right) ? ?_{F}\left(?_{1} D\left(e_{1}\right) ? ?_{2} D\left(e_{2}\right)\right) .
$$

Whether the outcome of an election produces an environmental or industrial government is a random process. The probability of electing an environmental government is denoted by $q_{1}, q_{2}, q_{F}$ for elections in state 1, state 2 and the federal level respectively. Each of these probabilities is influenced by the amount of lobbying done in each election by each special interest group ${ }^{7}$. We assume that each group can lobby in each election, but the environmental special interest groups lobby only for an environmental government and similarly for industrial special interest groups. Groups choose their lobbying effort to maximise their expected utility net of the costs of lobbying. We shall need to distinguish between gross and net utilities of special interest groups, where net utilities are gross utilities minus the costs of lobbying. In a similar way we shall distinguish between gross and net welfares of states.

To complete our broad description of the model, we assume that prior to any of the above activity taking place there will be two constitutional choices. The first is whether environmental policy should be set at the state level, in which case policy will be set by the state governments acting independently to maximise utility, so we will have a non-cooperative equilibrium and environmental dumping; or whether it is to be set at the federal level, in which case the federal government acts to maximise its utility, but there will be no environmental dumping. The second, independent, constitutional choice is between political discretion and social pooling. Under political discretion, state or federal governments will set policies to maximise utility, but the state governments will know their true damage costs. Under social pooling state or federal governments are mandated to implement policies which would maximise social welfare, based on the expected

\footnotetext{
${ }^{7}$ Note that if policy is set at the state level, then we need to track the types of governments elected in the two states. There are four configurations of state government types which we denote by $?_{s} ?\left(?_{1}, ?_{2}\right), s ? 1, \ldots, 4$, where: $?_{1} ?\left(?_{H}, ?_{H}\right) ; ?_{2} ?\left(?_{H}, ?_{L}\right), ?_{3} ?\left(?_{L}, ?_{H}\right) ; ?_{4} ?\left(?_{L}, ?_{L}\right)$ with respective probabilities: $Q_{s}, s=1$, $\ldots, 4$, where $Q_{1} ? q_{1} q_{2} ; Q_{2} ? q_{1}\left(1 ? q_{2}\right) ; Q_{3} ?\left(1 ? q_{1}\right) q_{2}$

$Q_{4}$ ? $\left(1 ? q_{1}\right)\left(1 ? q_{2}\right)$. If policy is set at the federal level then we need to know the configuration of government types elected in the two states and the federal government. There are eight configurations denoted:

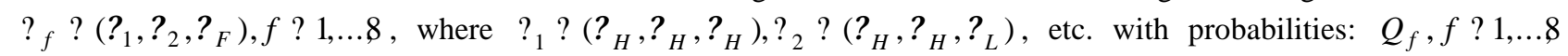
where $Q_{1} ? q_{1} q_{2} q_{F}, Q_{2} ? q_{1} q_{2}\left(1 ? q_{F}\right)$, etc.
} 
value of damage costs, ?. Since, as noted, both states have the same expected damage costs, social pooling will result in the same policies being set in each state (harmonisation).

We assume that the two constitutional choices will be based on the expected net welfare which each state expects to derive from the subsequent political process. In the various models of lobbying, even where there are biases, the two states will be ex ante identical, and so will be unanimous in the constitutional choices they make. Note that, although we are not explicit about the process of making constitutional choices, it is clearly different from the electoral process for selecting policy makers who then choose policies, because the criterion for choice is net welfare not net utility of an interest group. We have in mind that constitutional choices are usually made on a different basis from policy choices, using referenda, super-majorities etc. designed to more closely reflect 'the will of the people' than everyday political processes for making policy.

\subsection{The Game}

Formally we have a six stage game: in stage 1 there is a constitutional choice whether to set policy at state or federal level; and whether to have social pooling or political discretion. In stage 2, lobby groups decide how much lobbying effort to undertake in each election; in stage 3 elections are held; in stage 4 state governments learn their true damage costs; in stage 5 either state or federal governments set emission limits; finally in stage 6 firms set their levels of output and abatement. We now describe each stage in more detail.

\subsubsection{Stage 6: Firms Choose Outputs and Abatement}

Firm $i$ takes as given its emission limit, $e_{i}$, and the output of the other firm, $x_{j}$, and chooses its own output, $x_{i}$, and hence abatement, $a_{i} ? x_{i} ? e_{i}$, to maximise profits, net of abatement costs: $?\left(x_{i}, x_{j}, e_{i}\right) ? R\left(x_{i}, x_{j}\right) ? C\left(x_{i}\right) ? A\left(x_{i} ? e_{i}\right)$. The first-order condition is: $R_{1} ? C$ ? $A$ ? ? 0, i.e. marginal revenue equals marginal cost plus marginal abatement cost. Solving the pair of first-order conditions for the two firms yields the equilibrium outputs $X\left(e_{i}, e_{j}\right), j ? 1,2, i ? j$, and substituting back into the profit function yields the equilibrium profit function $?\left(e_{i}, e_{j}\right)$. From the equilibrium profit function we can derive the equilibrium (gross) welfare function for each state 
$W\left(e_{i}, e_{j}, ?{ }_{i}\right) ? ?\left(e_{i}, e_{j}\right) ? ?{ }_{i} D\left(e_{i}\right)$. Similarly, it is possible to define the equilibrium (gross) utility functions for each interest group: $U\left(e_{i}, e_{j}, ?_{i}, ?_{g}\right) ? ?\left(e_{i}, e_{j}\right) ? ?_{g}{ }_{i} D\left(e_{i}\right)$ and for each government; these have similar properties to the equilibrium welfare function.

\subsubsection{Stages 4 \& 5: State Governments Learn Damage Cost And Set Emission Limits}

We take these stages together since at the end of stage 4 each state government knows only its own damage cost parameter $?_{i}$ and this affects how governments set their emission limits. We consider separately the four cases depending on the constitutional choices at stage 1: whether policy is set at the state or federal level; and whether there is political discretion or social pooling.

\section{Policy set at the State level - Political Discretion}

For any given configuration of government types ${ }_{s}, s=1, \ldots, 4$ the emission limits in the two states are set as the equilibrium of a Nash game in which each state government knows its own damage costs but not those of its rival. So each state has to take as given the emission limits set by the other state depending on whether it has high or low damage costs. This means there are four equilibrium emission limits to be determined: $\tilde{e}_{1}\left(?_{s}, ?_{L}\right), \tilde{e}_{1}\left(?_{s}, ?_{H}\right), \tilde{e}_{2}\left(?_{s}, ?_{L}\right), \tilde{e}_{2}\left(?_{s}, ?{ }_{H}\right)$, and correspondingly four first-order conditions to determine them. For example, if state 1 has low damage costs, it will take as given the low damage cost and high damage cost emission limits of state 2 and choose $\tilde{e}_{1}\left(?_{s}, ?_{L}\right)$ to maximise expected utility:

$$
p U ? \tilde{e}_{1}\left(?_{s}, ?_{L}\right), \tilde{e}_{2}\left(?_{s}, ?_{L}\right), ?_{L}, ?_{1} ? ?(1 ? p) U ? \tilde{e}_{1}\left(?_{s}, ?_{L}\right), \tilde{e}_{2}\left(?_{s}, ?_{H}\right), ?_{L}, ?_{1} ?
$$

There will be three other similar first-order conditions: for state 1 with high damage costs, state 2 with low damage costs and state 2 with high damage costs.

Knowing the four equilibrium emission limits we can now calculate for configuration $s$ expected (gross) welfare of each state $i, \tilde{W}_{i s}$, and expected (gross) utility for each group $g, \tilde{U}_{g s}$. For example, for environmentalists in state 1 , we have ${ }^{8}$ :

\footnotetext{
${ }^{8}$ Where: $\tilde{U}_{1 s}\left(?_{L}\right) ? p U ? \tilde{e}_{1}\left(?_{s}, ?_{L}\right), \tilde{e}_{2}\left(?_{s}, ?_{L}\right), ?_{L}, ?_{H} ? ?(1 ? p) U \tilde{e}_{1}\left(?_{s}, ?_{L}\right), \tilde{e}_{2}\left(?_{s}, ?_{H}\right), ?_{L}, ?_{H} ?$ and $\tilde{U}_{1 s}\left(?_{H}\right) ? p U ? \tilde{e}_{1}\left(?_{s}, ?_{H}\right), \tilde{e}_{2}\left(?_{s}, ?_{L}\right), ?_{H}, ?_{H} ? ?(1 ? p) U ? \tilde{e}_{1}\left(?_{s}, ?_{H}\right), \tilde{e}_{2}\left(?_{s}, ?_{H}\right), ?_{H}, ?_{H} ?$.
} 


$$
\widetilde{U}_{1 s} ? p \widetilde{U}_{1 s}\left({ }_{L}\right) ?(1 ? p) \widetilde{U}_{1 s}\left(?_{H}\right)
$$

Policy set at the state level-Social Pooling

Irrespective of the configuration of government types, ${ }_{s}$, governments in each state are mandated to maximise expected welfare based on the expected value of damage costs. Thus the government in state $i=1,2$ takes as given the emission limit set the other state, $\bar{e}_{j}$, and sets its own emission limit $\bar{e}_{i}$ to maximise $W\left(\bar{e}_{i}, \bar{e}_{j}, ?\right)$, for which the first-order condition is $W_{1}\left(\bar{e}_{i}, \bar{e}_{j}, \bar{?}\right) ? 0$. In the resulting Nash equilibrium it is clear that since the two states are ex ante identical, the equilibrium emission limits will be equal, $\bar{e}_{i} ? \bar{e}_{j} ? \bar{e}$. Expected (gross) social welfare for state $i$ in configuration $s$ is simply $\bar{W}_{i s} ? \bar{W} ? W(\bar{e}, \bar{e}, \bar{?})$; similarly, for each special interest group $g$ in configuration $s$ expected (gross) utility is simply $\bar{U}_{g s} ? \bar{U}_{g} ? U\left(\bar{e}, \bar{e}, ?, ?{ }_{g}\right)$.

\section{Policy set at the federal level - Political Discretion}

For any configuration of three government types, $?_{f}, f=1, \ldots, 8$, the federal government needs to provide incentives for the state governments to reveal their private information. These incentives consist of both the choice of emission limits and the use of financial transfers, $M$. We assume that there is a cost of raising public funds to pay these transfers such that to raise 1 unit of the numeraire for public funds costs (1 ? ) units. Thus the federal government solves a standard mechanism design problem in which it asks state governments to announce their damage cost parameters, and depending on their announcements it will set each state an emission limit and a financial transfer. These are chosen to maximise the expected utility of the federal government, net of the cost of raising public funds, subject to both a set of incentive compatibility constraints, to ensure the state governments reveal their true damage costs, and a set of individual rationality constraints, that no state government with its given political weight and damage cost parameter would be worse off than in the case where environmental policy was set at the state level. It is because these incentive compatibility constraints and individual rationality constraints are expressed in terms of the utilities of the state governments, and hence depend on the type of state governments elected, that the choice 
of emission limits depends on the types of all governments, and not just on the type of the federal government.

Formally, the federal government must choose the set of policy instruments ${ }^{9}: \hat{e}_{L L}^{1}, \hat{e}_{L H}^{1}$, $\hat{e}_{H L}^{1}, \hat{e}_{H H}^{1}, \hat{e}_{L L}^{2}, \hat{e}_{L H}^{2}, \hat{e}_{H L}^{2}, \hat{e}_{H H}^{2}, M_{L}^{1}, M_{H}^{1}, M_{L}^{2}, M_{H}^{2}$ to maximise:

$$
\begin{aligned}
& p^{2 !} U\left(\hat{e}_{L L}^{1}, \hat{e}_{L L}^{2}, ?_{L}, ?_{F}\right) ? M_{L}^{1} ? U\left(\hat{e}_{L L}^{2}, \hat{e}_{L L}^{1}, ?_{L}, ?_{F}\right) ? M_{L}^{2} ? \\
& ? p(1 ? p) ?^{\eta} U\left(\hat{e}_{L H}^{1}, \hat{e}_{H L}^{2}, ?_{L}, ?_{F}\right) ? M_{L}^{1} ? U\left(\hat{e}_{H L}^{2}, \hat{e}_{L H}^{1}, ?_{H}, ?_{F}\right) ? M_{H}^{2} ? \\
& ? p(1 ? p) ?^{\eta} U\left(\hat{e}_{H L}^{1}, \hat{e}_{L H}^{2}, ?_{H}, ?_{F}\right) ? M_{H}^{1} ? U\left(\hat{e}_{L H}^{2}, \hat{e}_{H L}^{1}, ?_{L}, ?_{F}\right) ? M_{L}^{2} ? \\
& ?(1 ? p)^{2} ! U\left(\hat{e}_{H H}^{1}, \hat{e}_{H H}^{2}, ?{ }_{H}, ?{ }_{F}\right) ? M_{H}^{1} ? U\left(\hat{e}_{H H}^{2}, \hat{e}_{H H}^{1}, ?_{H}, ?_{F}\right) ? M_{H}^{2} ? \\
& ?(1 ? ?)\left\{p M_{L}^{1} ?(1 ? p) M_{H}^{1} ? p M_{L}^{2} ?(1 ? p) M_{H}^{2}\right\}
\end{aligned}
$$

subject to the incentive compatibility constraints:

$$
\begin{aligned}
& p U\left(\hat{e}_{L L}^{1}, \hat{e}_{L L}^{2}, ?_{L}, ?_{1}\right) ?(1 ? p) U\left(\hat{e}_{L H}^{1}, \hat{e}_{H L}^{2}, ?_{L}, ?_{1}\right) ? M_{L}^{1} ? \\
& p U\left(\hat{e}_{H L}^{1}, \hat{e}_{L H}^{2}, ?_{L}, ?_{1}\right) ?(1 ? p) U\left(\hat{e}_{H H}^{1}, \hat{e}_{H H}^{2}, ?_{L}, ?_{1}\right) ? M_{H}^{1} \\
& p U\left(\hat{e}_{H L}^{1}, \hat{e}_{L H}^{2}, ?_{H}, ?_{1}\right) ?(1 ? p) U\left(\hat{e}_{H H}^{1}, \hat{e}_{H H}^{2}, ?_{H}, ?_{1}\right) ? M_{H}^{1} ? \\
& p U\left(\hat{e}_{L L}^{1}, \hat{e}_{L L}^{2}, ?_{H}, ?_{1}\right) ?(1 ? p) U\left(\hat{e}_{L H}^{1}, \hat{e}_{H L}^{2}, ?_{H}, ?_{1}\right) ? M_{L}^{1} \\
& p U\left(\hat{e}_{L L}^{2}, \hat{e}_{L L}^{1}, ?_{L}, ?_{2}\right) ?(1 ? p) U\left(\hat{e}_{L H}^{2}, \hat{e}_{H L}^{1}, ?_{L}, ?_{2}\right) ? M_{L}^{2} ? \\
& p U\left(\hat{e}_{H L}^{2}, \hat{e}_{L H}^{1}, ?_{L}, ?_{2}\right) ?(1 ? p) U\left(\hat{e}_{H H}^{2}, \hat{e}_{H H}^{1}, ?_{L}, ?_{2}\right) ? M_{H}^{2} \\
& p U\left(\hat{e}_{H L}^{2}, \hat{e}_{L H}^{1}, ?_{H}, ?_{2}\right) ?(1 ? p) U\left(\hat{e}_{H H}^{2}, \hat{e}_{H H}^{1}, ?_{H}, ?{ }_{2}\right) ? M_{H}^{2} ? \\
& p U\left(\hat{e}_{L L}^{2}, \hat{e}_{L L}^{1}, ?_{H}, ?_{2}\right) ?(1 ? p) U\left(\hat{e}_{L H}^{2}, \hat{e}_{H L}^{1}, ?_{H}, ?_{2}\right) ? M_{L}^{2}
\end{aligned}
$$

\footnotetext{
9 To save notation we omit the dependence of these policy instruments on the configuration of government types $?_{f}$. The symbol $\hat{e}_{L H}^{1}$ denotes the emission limit that will be set in state 1 if state 1 declares it has low damage costs and state 2 declares it has high damage costs; it can differ from $\hat{e}_{H L}^{2}$, the emission limit set in state 2 if it declares it has low damage costs and state 1 declares it has high damage costs because states 1 and 2 may have different government types. $\hat{M}_{H}^{1}$ is the transfer to state 1 if it declares it has high damage costs. In principle these transfers could be distinguished by what both states declare as damage costs, but this would add nothing.
} 
and the individual rationality constraints: $:^{10}$

$$
\begin{aligned}
& p U\left(\hat{e}_{L L}^{1}, \hat{e}_{L L}^{2}, ?_{L}, ?_{1}\right) ?(1 ? p) U\left(\hat{e}_{L H}^{1}, \hat{e}_{H L}^{2}, ?_{L}, ?_{1}\right) ? M_{L}^{1} ? \tilde{U}_{1 s}\left(?_{L}\right) \\
& p U\left(\hat{e}_{L H}^{1}, \hat{e}_{H L}^{2}, ?_{H}, ?_{1}\right) ?(1 ? p) U\left(\hat{e}_{H H}^{1}, \hat{e}_{H H}^{2}, ?_{H}, ?_{1}\right) ? M_{H}^{1} ? \tilde{U}_{1 s}\left(?_{H}\right) \\
& p U\left(\hat{e}_{L L}^{2}, \hat{e}_{L L}^{1}, ?_{L}, ?_{2}\right) ?(1 ? p) U\left(\hat{e}_{L H}^{2}, \hat{e}_{H L}^{1}, ?_{L}, ?_{2}\right) ? M_{L}^{2} ? \tilde{U}_{2 s}\left(?_{L}\right) \\
& p U\left(\hat{e}_{H L}^{2}, \hat{e}_{L H}^{1}, ?_{H}, ?_{2}\right) ?(1 ? p) U\left(\hat{e}_{H H}^{2}, \hat{e}_{H H}^{1}, ?_{H}, ?_{2}\right) ? M_{H}^{2} ? \tilde{U}_{2 s}\left(?_{H}\right)
\end{aligned}
$$

The utilities on the right-hand side of the individual rationality constraints are derived from the solution to the model when policy is set at the state level as set out in section 2.3.1 above; the configuration ? ${ }_{s}$ of types of state governments whose utilities are used on the RHS of equation (2) is the same as the configuration of state government types found in configuration ${ }_{f}$ for which the mechanism design problem is being solved.

Incentive compatibility constraints (1a) and (1b) are for state 1 with low and high damage costs respectively, while (1c) and (1d) are for state 2 with low and high damage costs respectively. Similarly individual rationality constraints $(2 a)$ and $(2 b)$ are for state 1 with low and high damage costs, while (2c) and (2d) are for state 2 with low and high damage costs respectively.

So for any configuration of government types, $f$, we solve the mechanism design problem above. We can then calculate expected welfare for each state $i=1,2, \hat{W}_{i f}$, and expected utility for each group $g=1, \ldots, 4, \hat{U}_{g f}$. The calculation of the expressions is straightforward, but we omit the details because they are cumbersome to write out.

\footnotetext{
${ }^{10}$ Our justification for imposing these constraints even though a prior constitutional stage has decided that policy should be set at the federal level is that it may represent less formal structures such as the EU. Here, even at the implementation stage, state governments may an incentive to defect from the constitutionally agreed decision.
} 


\section{Policy Set at the Federal Level - Social Pooling}

Again, irrespective of the configuration of government types, $?_{f}$, the federal government is mandated to maximise total expected welfare based on the expected value of damage costs. Thus the federal government chooses $e^{*}{ }_{1}, e^{*}{ }_{2}$ to maximise $W\left(e_{1}^{*}, e_{2}{ }^{*}, \bar{?}\right) ? W\left(e_{2}{ }^{*}, e_{1}{ }^{*}, \bar{?}\right)$, for which the first-order condition is $W_{1}\left(e_{1}^{*}, e_{2}{ }^{*}, \bar{?}\right) ? W_{2}\left(e_{2}{ }^{*}, e_{1}{ }^{*}, \bar{?}\right) ? 0$. Again it is clear that since the two states are identical ex ante, the solution must require $e^{*}{ }_{1} ? e^{*}{ }_{2} ? e^{*}$. Expected (gross) social welfare for each state $i$ in each configuration $f$ is simply $W_{i f} *$ ? $W^{*} ? W\left(e^{*}, e^{*}, \bar{?}\right)$; while expected (gross) utility for interest group $g$ in configuration $f$ is simply $U_{g f}^{*} ? U_{g} * ? U\left(e^{*}, e^{*}, \overline{,}_{,},{ }_{g}\right)$.

If we compare the two constitutional choices involving social pooling, it is clear from the properties of the welfare function that $e^{*} ? \bar{e}, W^{*} ? \bar{W}$, so that if social pooling is chosen at the constitutional stage, then it always be better to have environmental policy set at the federal level. Note the important point that social pooling implies that environmental policies will be harmonised across the two states, no matter what the ex post level of damage costs turns out to be in the two states.

\subsubsection{Stage 3: Elections}

Let $x_{g i}$ be the amount of lobbying done by group $g$ in election $i=1,2, F$, and assume that the probability of electing an environmental government in election $i$ is given by:

$$
q_{i} ? \frac{1 ? x_{1 i} ? x_{2 i}}{2 ? X_{i}} \quad \text { where } X_{i} ? \stackrel{g ? 4}{?} x_{g i 1}
$$

Note that in the absence of lobbying the probability of electing an environmental government is 0.5. Note also that we are assuming that special interest groups based in a particular state can lobby in elections in 'foreign' states, as well as in their home state and in federal elections. This reflects the view that multinational companies will seek to use their influence globally, and environmental NGO's are responding by operating multinationally. However we assume that interest groups of the

Actually, these constraints are frequently not binding, so we do not believe our result would be sensitive to dropping them. 
same type based in different states lobby non-cooperatively; an obvious extension would be to model cooperative lobbying.

It is straightforward to show that that $0<q_{i}<1$ and that:

$$
\begin{array}{lll}
\frac{? q_{i}}{? x_{g i}} ? \frac{\left(1 ? q_{i}\right)}{\left(2 ? X_{i}\right)} ; & \frac{?^{2} q_{i}}{? x_{g i}^{2}} ? \frac{2\left(1 ? q_{i}\right)}{\left(2 ? X_{i}\right)^{2}} ; & g=1,2, \\
\frac{? q_{i}}{? x_{g i}} ? \frac{q_{i}}{\left(2 ? X_{i}\right)} ; & \frac{?^{2} q_{i}}{? x_{g i}^{2}} ? \frac{2 q_{i}}{\left(2 ? X_{i}\right)^{2}} ; & g=3,4 .
\end{array}
$$

So $q_{i}$ is an increasing, concave function of lobbying efforts by environmental groups and a decreasing convex function of lobbying efforts by industrial groups.

Since these probabilities depend on choices of lobbying at prior stages of the game, and these choices, in general, will differ depending on which of the four constitutional choices have been made. If policy is set at the state level, we shall denote by $\tilde{Q}_{s}$ and $\bar{Q}_{s}$ the probabilities of configuration of government types $?_{s}, s=1, \ldots, 4$ occurring with political discretion and social pooling respectively. The previous section allows us to calculate expected (gross) welfares and utilities $\tilde{W}_{i s}, \tilde{U}_{g s}$ with political discretion, and $\bar{W}_{i s}, \bar{U}_{g s}$ with social pooling. So we can now take expectations over all possible configurations $?_{s}$ to derive the expected gross welfare and utility for each state and group with political discretion and social pooling respectively as:

$\tilde{W}_{i} ? \stackrel{s ? 4}{?} \tilde{Q}_{s} \tilde{W}_{i s} ; \quad \tilde{U}_{g} ? \stackrel{s ? 4}{?} \tilde{Q}_{s ? 1} \tilde{U}_{g s} ; \quad \bar{W}_{i} ? \stackrel{s ? 4}{?} \bar{Q}_{s ? 1} \bar{W}_{i s} ; \quad \bar{U}_{g} ? \stackrel{s ? 4}{?} \bar{Q}_{s} \bar{U}_{g s}$

Similarly, if policy is set at the federal level, we denote the probabilities of configuration of government types, $?_{f}, f=1, \ldots, 8$ occurring with political discretion and social pooling by $\hat{Q}_{f}$ and $Q_{f}^{*}$ respectively. So we can calculate expected (gross) welfares and utilities across all configurations $?_{f}, f=1, \ldots, 8$ with political discretion and social pooling respectively by:

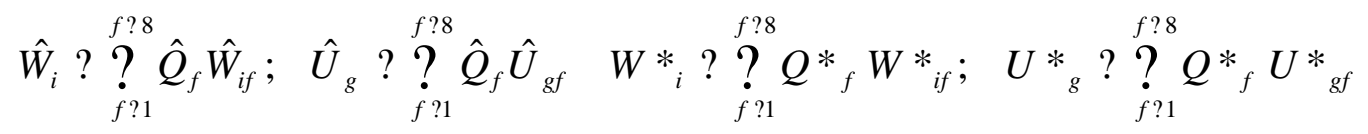




\subsubsection{Stage 2: Lobbying}

Assume that if group $g$ expends lobbying effort $x_{g i}$ in election $i$ then it incurs a cost $0.5 ?_{g i} \cdot\left(x_{g i}\right)^{2}$ where $?_{\mathrm{gi}}$ is a parameter which, as we shall see, can be varied to allow for the three asymmetries referred to in the introduction. We now determine the levels of lobbying effort by each special interest group in each election, and hence the probabilities of different types of government being elected for the four possible constitutional choices.

\section{Policy Set at State Level - Political Discretion}

It is clear that since the type of federal government has no influence on utilities or welfare, and since lobbying is costly, each interest group $g$ will not lobby at the federal level. Denote by $\tilde{x} ?\left(\tilde{x}_{11}, \tilde{x}_{12}, \ldots, \tilde{x}_{41}, \tilde{x}_{42}\right)$ the vector of eight lobbying efforts $\tilde{x}_{g i}$ by interest group $g=1, \ldots, 4$ in the election in state $i=1,2$. Denote by $\tilde{Q}_{s}(\tilde{x})$ the probability of electing configuration ${ }_{s}$ of state governments, given $\tilde{x}$. Then each special interest group will take as given the lobbying efforts by all other groups and choose $\tilde{x}_{g 1}$ and $\tilde{x}_{g 2}$ to maximise

$$
\stackrel{s ? 4}{?} \tilde{Q}_{s}(\tilde{x}) \tilde{U}_{g s} ? \stackrel{i ? 2}{?}\left[0.5 ?_{g i}\left(\tilde{x}_{g i}^{2}\right)\right]
$$

There will be eight first-order conditions, where e.g. the first-order condition for $\tilde{x}_{g 1}$ is:

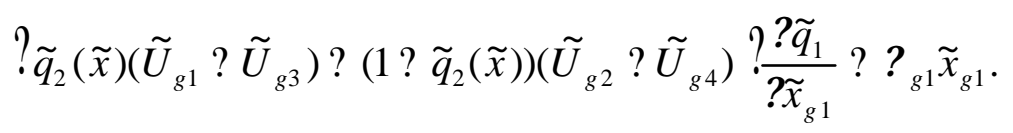

(4) has a standard interpretation. The RHS is the marginal cost of lobbying by group $g$ in state $i$ and the LHS is the marginal benefit, where the term in square brackets is the difference in expected utility to group $g$ from having an environmental rather than industrial government in state $i$, and the remaining term is just the marginal effect on the probability of having an environmental government elected in state 1 from a bit more lobbying by group $g$. $\tilde{x}$ is the solution to the eight first-order conditions (4). Define equilibrium lobbying costs as $\tilde{K}_{g}(\tilde{x}) ? ?^{i ? 2}{ }_{i ? 1}^{i ?} 0.5 ?_{g i}\left(\tilde{x}_{g i}\right)^{2}$. We can now establish the equilibrium levels of gross utility for each interest group and gross welfare for each state: 


$$
\begin{array}{rlr}
\tilde{U}_{g}^{G} ? ?_{s ? 1}^{s ? 4} \tilde{Q}_{s}(\tilde{x}) \tilde{U}_{g s}, & g=1, \ldots, 4, \\
\tilde{W}_{i}^{G} ? \stackrel{s ? 4}{?} \tilde{Q}_{s ? 1}(\tilde{x}) \tilde{W}_{i s}, & i=1,2 .
\end{array}
$$

Similarly, equilibrium levels of net utility for each group and net welfare for each state are:

$$
\begin{array}{lll}
\tilde{U}_{g}^{N} ? \tilde{U}_{g}^{G} ? \tilde{K}_{g}(\tilde{x}), & g=1, \ldots, 4 . \\
\tilde{W}_{i}^{N} ? \tilde{W}_{i}^{G} ? ?_{g} \tilde{K}_{g}(\tilde{x}) & \text { for } i=1, g=1,3 \text {; for } i=2, g=2,4 .
\end{array}
$$

Policy Set at State level - Social Pooling

The lobbying equilibrium is trivial for social pooling. Since for each group $g \bar{U}_{g s} ? \bar{U}_{g} \quad s$ ? $1, \ldots 4$, i.e. expected utility is the same for all configurations of government types it makes no sense to incur any lobbying expenditure to change the probabilities of different electoral outcomes. So $\bar{x}_{g i} ? 0 \quad ? g, i, \quad$ and hence $\bar{Q}_{s} ? 0.25 \quad s \quad=1, \ldots, 4$. Thus $\bar{U}_{g}^{G} ? \bar{U}_{g}^{N} ? \bar{U}_{g} \quad g ? 1, \ldots, 4$; $\bar{W}_{i}^{G} ? \bar{W}_{i}^{N} ? \bar{W} \quad i ? 1,2$.

\section{Policy Set at Federal Level - Political Discretion}

We proceed in a similar way when policy is set at the federal level. $\hat{x} ?\left(\hat{x}_{g i}\right)$ is the vector of lobbying efforts by groups $g=1, \ldots, 4$ in elections $i=1,2, F \cdot \hat{Q}_{f}(\hat{x})$ is the probability of electing configuration ${ }_{f}, f=1, \ldots, 8$ of governments types given lobbying efforts $\hat{x}$. Interest group $g$ takes as given the lobbying efforts by all other groups and chooses $\hat{x}_{g 1}, \hat{x}_{g 2}$ and $\hat{x}_{g F}$ to maximise

$$
\stackrel{f ? 8}{?} \hat{Q}_{f ? 1}(\hat{x}) \hat{U}_{g f} ? \stackrel{i ? F}{?} 0.5 ?_{g i}\left(\hat{x}_{g i}^{2}\right) \text {. }
$$

There will be 12 first-order conditions to determine $\hat{x}$ where, for example, the first-order condition for $\hat{x}_{g F}$ is:

$$
\begin{array}{r}
?_{g F} \hat{x}_{g F} ? \frac{? \hat{q}_{F}(\hat{x})}{? \hat{x}_{g F}} ? \hat{q}_{1} \hat{q}_{2}\left(\hat{U}_{g 1} ? \hat{U}_{g 5}\right) ? \hat{q}_{1}\left(1 ? \hat{q}_{2}\right)\left(\hat{U}_{g 2} ? \hat{U}_{g 6}\right) ? \\
\left(1 ? \hat{q}_{1}\right) \hat{q}_{2}\left(\hat{U}_{g 3} ? \hat{U}_{g 7}\right) ?\left(1 ? \hat{q}_{1}\right)\left(1 ? \hat{q}_{2}\right)\left(\hat{U}_{g 4} ? \hat{U}_{g 8}\right) ?
\end{array}
$$


Equation (5) has exactly the same interpretation as equation (4). We solve these 12 first-order conditions simultaneously to determine the equilibrium vector of lobbying effort $\hat{x}$. Then define equilibrium lobbying costs for each group by $\hat{K}_{g}(\hat{x}) ? ?^{i ? F}{ }_{i ? 1}^{i ?} 0.5 ?{ }_{g i}\left(\hat{x}_{g i}\right)^{2}$.

The equilibrium levels of gross utility for each interest group and gross welfare for each state are:

$$
\begin{array}{ll}
\hat{U}_{g}^{G} ?{ }^{?}{ }_{f ? 1}^{f ? 8} \hat{Q}_{f}(\hat{x}) \hat{U}_{g f}, & g=1, . ., 4, \\
\hat{W}_{i}^{G} ? ?^{f ? 8}{ }_{f ? 1}^{f ?} \hat{Q}_{f}(\hat{x}) \hat{W}_{i f}, & i=1,2,
\end{array}
$$

and the equilibrium levels of net utility for each group and net welfare for each state are

$$
\begin{array}{lll}
\hat{U}_{g}^{N} ? \hat{U}_{g}^{G} ? \hat{K}_{g}(\hat{x}), & g=1, . ., 4, \\
\hat{W}_{i}^{N} ? \hat{W}_{i}^{G} ? ?_{g} \hat{K}_{g}(\hat{x}) & \text { for } i=1, g=1,3 ; \text { for } i=2, g=2,4 .
\end{array}
$$

Policy Set at Federal Level - Social Pooling

For the same reasons as with social pooling at the state level, it will not pay any group to incur any lobbying expenditure, so $x_{g i}^{*}$ ? 0 ? $g, i ; Q_{f}^{*}$ ? 0.125, $f=1, \ldots, 8 ; U_{g}^{* G}$ ? $U_{g}^{* N}$ ? $U^{*} g$ ? $1, \ldots, 4$; $W_{i}^{* G} ? W_{i}^{* N} ? W^{*} i ? 1,2$.

\subsubsection{Stage 1: Constitutional Choice}

Which of the four possible constitutional choices - political discretion at the federal level, political discretion at the state level, social pooling at the federal level, or social pooling at the state level will be selected depends on the net expected welfare for each state: $\hat{W}_{i}^{N}, \tilde{W}_{i}^{N}, W_{i}^{*}{ }^{*}, \bar{W}_{i}^{N}$. The choice will be the one which gives both states the highest net welfare. 


\section{A Special Case - Results Without Lobbying}

\subsection{Special Case}

In this section we set out a special case we employed in Johal and Ulph (2001a,b). The two firms produce a homogenous good and face a linear inverse demand function with intercept $A$ and unit slope. There are no costs of production but there are quadratic abatement costs, $0.5 a^{2}$ and the damage cost is a quadratic function of total pollution: $D\left(e_{i}\right) ? 0.5\left(e_{i}\right)^{2}$. It is then straightforward to show that the utility function for state $i$ is:

$$
U\left(e_{i}, e_{j}, ?_{i}, ?_{i}\right) ? 3\left(2 A ? e_{j}\right)^{2} ? 18 e_{i}\left(2 A ? e_{j}\right) ?\left(37 ? 64 ?_{i} ?_{i}\right) e_{i}^{2}
$$

We assume that $p=0.5$ and that $?_{H}$ ? (1? ?)?; $?_{L} ?(1 ? ?) \overline{\text { ? }}$ where $0<?<1$, and ? is a measure of the dispersion of damage costs around expected value. Similarly we assume that $?_{H}$ ? 1??; $?_{L}$ ? 1? ? where $0<?<1$ and ? is a measure of the dispersion of political weights for environmental damage costs.

\subsection{Results without active lobbying}

We summarise the results obtained in Johal and Ulph (2001a) when there is no active lobbying, which would arise if the costs of lobbying, ? ${ }_{g i}$, are sufficiently high to make lobbying uneconomic. In this case, there is no distinction between gross and net utilities or welfares, and because states are ex ante identical we can simplify notation and denote the welfare levels for each state under the four constitutional choices: social pooling at federal and state evel, political discretion at state and federal level by $W^{*}(\bar{?}), \bar{W}(\bar{?}), \hat{W}(?, ?, ?), \tilde{W}(?, ?, ?)$ respectively; this notation shows that with social pooling expected welfare depends only on expected damage costs while with political discretion it also depends on the degrees of dispersion of damage costs and preferences of special interest groups. In Johal and Ulph (2001a) we proved the following results ${ }^{11}$ :

Result 1: $W^{*}(\bar{?}) ? \bar{W}(\bar{?}) \quad ? ?$ ?. With social pooling, states are at least as well off if policy is set at the federal level than if it is set at the state level.

\footnotetext{
${ }^{11}$ These results were proved analytically using approximation arguments and so strictly hold for small values of ? and? ; however they were also confirmed by numerical results for a wide range of parameter values.
} 
Result 2: $\hat{W}(?, ?, ?) ? \tilde{W}(\bar{?}, ?, ?) \quad ? ?, ?, ?$. With political discretion, states are at least as well off if policy is set at the federal level than if it is set at the state level.

These results show that the benefits from eliminating policy competition between the states are greater than welfare losses due to either informational problems or activities of special interest groups.

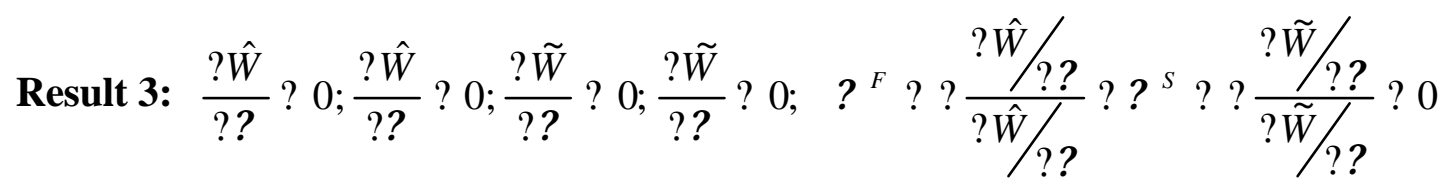

Whether policy is set at the state or federal level, expected welfare with political discretion increases with the dispersion in damage costs and decreases with the dispersion of preferences of special interest groups.

This result shows that the benefit from political discretion in being able to fine-tune policies to actual damage costs increases as the dispersion of damage costs increases, while the cost of political discretion from having policy influenced by special interest groups also increases as the dispersion of preferences of special interest groups increases. The slope of iso-welfare contours for political discretion in $(?, ?)$ space when policy is set at the federal level, ${ }^{F}{ }^{F}$, is greater than the slope of isowelfare contours when policy is set at the state level, ${ }^{S}$.

Result 4: $\hat{W}(\bar{?}, 0,0) ? W^{*}(\bar{?}) ; \quad \tilde{W}(\bar{?}, 0,0) ? \bar{W}(\bar{?}) \quad ? ?$ ?. Whether policy is set at the federal or state level, political discretion yields the same welfare as social pooling when the dispersions of damage costs and preferences of special interest groups are zero.

Result 4 is obvious. Putting together Results 3 and 4, for any value of ? we can think of a constitutional indifference curve in $(?, ?)$ space between political discretion and social pooling when policy is set at the federal level, and similarly when policy is set at the state level. These indifference curves show the combinations of $(?, ?)$ for which political discretion and social polling yield equal welfare. Results 3 and 4 show that these indifference curves pass through the origin, are upward sloping and that the federal indifference curve lies everywhere above the state indifference 
curve (see Figure 1). For points lying above these indifference curves (i.e. when there is a relatively large dispersion of preferences of special interest groups and relatively low dispersion of damage costs), social pooling is preferred to political discretion, while for points lying below these indifference curves, political discretion is preferred to social pooling. We can then define four possible regimes: I social pooling is preferred to political discretion at both state and federal level; II political discretion is preferred to social pooling at both state and federal level; III political discretion is preferred to social pooling at the federal level, but social pooling is preferred to political discretion at the state level; IV social pooling is preferred to political discretion at the federal level but political discretion is preferred to social pooling at the state level. Then the fact that the federal level indifference curve lies everywhere above the state indifference curve (other than at the origin) yields:

\section{Result 5: There are no parameter values for which Regime IV would be the outcome.}

Recalling that social pooling implies harmonisation of policies, what this result says is that the need to have policy set at the federal level rather than the state level to overcome policy competition could never lead to the harmonisation of policies if they had not already been harmonised (albeit at a laxer level) when policy had been set at the state level.

In the next section we discuss how these results are affected by assuming that lobbying costs are low enough to ensure that lobbying takes place. 


\section{The Effects Of Introducing Active Lobbying.}

\subsection{General Considerations}

Introducing active lobbying has two main effects. Firstly, unless the lobbying equilibrium produces symmetric lobbying effort between environmentalists and industrialists, the probability of electing an environmental government in any given election will no longer be 0.5 , and hence the probabilities of different configurations of government types will change. This will affect both the expected utilities of different interest groups and expected state welfares. An interest group is better off if there is an increased probability of a configuration which has a government of its own type in office through simple direct preference association. This is true whether policy is set at the federal or state levels. When policy is set at the state level though, there are the additional, indirect, effects of strategic competition. In terms of profits, both domestic firms are better off if the government of the rival state is environmental. An environmental government will impose tougher emission standards and so restrict its domestic firm's output, allowing the rival firm to expand its output. Furthermore, if both states have environmental governments then the tougher standards will result in both firms reducing output but in so doing so will move output closer to the monopoly level, raising the profits of both firms. Also, of course, the reduced output means lower pollution levels so that there is a double gain and welfare is unambiguously raised. The state configuration where there are two industrial governments in power will obviously have the opposite effects. When policy is set at the federal level then the configuration of state government types will become less important although they will have some influence through the impact of the incentive compatibility and individual rationality constraints in equations (1) and (2). The problem of environmental dumping is internalised when policy is set at the federal level and this results in both lower pollution of course but also higher profits by restricting output and reducing excessive competition. The second effect is simply that lobbying costs are pure waste and so reduce net expected utilities and welfare.

We now note how lobbying effort and the cost of lobbying vary with the various parameters within our model. Firstly, ? $X_{i} / ? ? ? 0, ?^{2} X_{i} / ? ?^{2} ? 0$, that is lobbying effort is a decreasing concave function of the lobbying cost parameter. The sharp reduction in lobbying effort means that lobbying costs fall as ? ?ncreases. ? $X_{i} /$ ?? ? 0 for low values of ? but for higher values ? $X_{i} / ? \bar{?}$ ? 0 . This reflects the fact that if damage costs are either very low or very high there is not much variation in 
policies across different government types (in the first case even environmentalists would not want much regulation, in the second even industrialists would want tight regulation). If $?=?=0$ so that the states are identical, no lobbying is worthwhile and so Result 4 in section 3.2 will still hold. ? $X_{i} /$ ?? ? 0 so, as we would expect, as the ideological positions of the two groups become more polarised more lobbying takes place. Finally, except for rather low values of ? , ? $X_{i} /$ ?? ? 0, so greater dispersion in damage costs between the two states will induce greater levels of lobbying.

Now we are interested in how far the results of section 3.2 derived for the case of no lobbying carry over when there is active lobbying. It is immediately obvious that since there is no lobbying with social pooling, Result 1 carries over even if lobbying costs are low, so with social pooling it is always better to set policy at the federal level. The results we are interested in then are whether it always better to have policy set at federal level than at the state level with political discretion and active lobbying, and the comparison between social pooling and political discretion when there is active lobbying with political discretion, and in particular whether Result 5 in section 3.2 still holds. We discuss these in reverse order.

As noted we are going to have to rely on numerical solutions to derive the full equilibrium with political discretion and active lobbying. We set the parameter for the level of demand, $A=10$, and the social cost of raising public funds $s=0.3$. Neither is a key parameter. For expected damage costs we work with values $?=0.1,0.3, \ldots, 0.9$, which as noted in Johal and Ulph $(2001 b)$ would imply that in a world with no environmental policy damage costs would lie between $7.5 \%$ and $67.5 \%$ of profits (GNP). Two other key parameters are ?,? the dispersion of damage costs and political weights attached to damage costs respectively. Since we want to map out the indifference curves between social pooling and political discretion in ?? ? space, or equivalently calculate the proportions of ? ? ? space that lie in each of the four Regimes I to IV, we take a fairly fine grid on these parameters, with each taking the 39 values $0.025,0.05, \ldots, 0.975$, giving a grid of 1521 points. The final key set of parameters are the lobbying costs $?_{g i}$. We work mainly with values of 1 and 10. In the case of symmetric lobbying, $?_{g i} ?$ ?, and parameter values ? ? 0.3, ? ? ? 0.5, these values of ? produce welfare losses when policy is set at the federal level between $0.8 \%$ and $1.3 \%$ of GNP, which is well within the range found by Katz and Rosenberg (1994) who calculated the 
costs of rent seeking as a percentage of GNP for a number of countries, and showed that this varied from $0.19 \%$ to $5.43 \%$. However, in some cases we have explored a wider range of values for ? .

\subsection{Social Pooling or Political Discretion?}

In this sub-section we ask how active lobbying affects the comparison of expected net welfare between social pooling and political discretion. More specifically we are interested in what happens to the indifference curves between social pooling and political discretion in ?? space, or equivalently the proportions of ? ? space that lie in each of the four Regimes I to IV. As already noted, expected net welfare with social pooling remains unaffected, so the question is how active lobbying affects expected net welfare with political discretion.

\subsubsection{Symmetric Lobbying}

We begin by considering symmetric lobbying costs $?_{g i} ? ? \quad ? g, i$. To understand what happens to expected gross and net welfare, we need to begin by summarising the pattern of lobbying that arises, as reported in Johal and Ulph (2001b). When policy is set at the state level environmental groups lobby both states, and in fact lobby the other state more intensively, while industry groups lobby only their own state. The rationale for these patterns follows from the point made above, that, whether policy is set at state or federal level, domestic profits are always higher when the other state government is environmental. To encourage this outcome, domestic environmental groups lobby for the rival state environmental party, but domestic industrialists desist from lobbying for the rival industrial party. The second thing to note is that lobbying effort by environmentalists exceeds that by industrialists. This reflects the fact that having environmental governments can be beneficial to industry if that results in industry output which gets closer to the monopoly level. Of course, this results in the probability of an environmental government being markedly higher than 0.5 .

When policy is set at the federal level the difference in lobbying effort between the groups is not so pronounced. Environmental groups now lobby only in the rival state while industrialists still lobby only in their own state. All groups shift some of their lobbying effort to the federal level but environmental groups relatively more so. Industrialists now do more lobbying at the state level than at the federal level, while environmentalists lobby more than industrialists at the federal level. This 
results in increasing the probability of electing an environmental government at the federal level but reducing it at the state level. The rationale behind the pattern of lobbying is similar to before. Environmental groups realise it is the federal government which determines policies and so they concentrate their efforts at that level. Industrialists though realise that an environmental government at the federal level will impose tougher emission limits but in so doing increase the firms' market power and so are less inclined to exert extra resources at that level.

To assess the implications of introducing symmetric lobbying for the choice between social pooling and political discretion consider Table 1, where we use the parameter values ? 0.3 , and, for the symmetric lobbying case, ? ? 1. In the first column we show the percentage of the 1521 combinations of ? and? which lie in each of the four Regimes I ... IV with No Lobbying, and, as we showed in section 3.2, there are no values which lie in Regime IV. Columns 2 and 3 present the results for symmetric lobbying. In the third column we present the corresponding percentages for the case of active lobbying. But to understand the changes we have broken the overall change down into the two effects identified in 4.1. Thus in column 2 we show what happens if we ignore the costs of lobbying and consider only what happens to gross welfare due to the change in probabilities of different configurations of government types due to lobbying. To get to column 3 we then include the costs of lobbying and calculate net welfare. Finally, to help understand what is happening we show in the last two rows of columns 2 and 3 the average \% change in expected welfare with political discretion when policy is set at the federal and state level respectively, averaged over all values of ? and? .

Thus, moving from column 1 to column 2 we see that the introduction of active lobbying increases expected gross welfare because it increases the probability of electing green governments. This increase in expected gross welfare is greater when policy is set at the state level than at the federal level, partly because the increase in probability of electing a green government is greater but also because having a green government matters more when there is strategic competition between states. In terms of what happens to the indifference curves between political discretion and social pooling, both move upwards, but more so for the state than the federal level (Figure 2a shows the indifference curves for No Lobbying and Symmetric Lobbying with gross welfare). This means that Regime I (social pooling preferred at both levels) is reduced somewhat, while Regime II (political discretion preferred at both levels) increases quite markedly; this is because, without lobbying, the 
indifference curve at state level lay below the indifference curve at federal level, so the marked increase in the state level indifference curve has a big impact on Regime II, which lies below the two indifference curves, and less impact of Regime I, which lies above both indifference curves. Regime III (political discretion preferred at the federal level, social pooling at the state) gets squeezed sharply, and now there is a similar proportion of Regime IV (social pooling preferred at the federal level, political discretion at the state level), again because the state indifference curve has now moved above the federal indifference curve in places.

When we introduce lobbying costs and move from column 2 to column 3 we see that lobbying costs have reduced expected welfare when policy is set at the federal level on average by $1.8 \%$, and by $2.25 \%$ when it is set at the state level. This reflects the fact that lobbying costs are greater when policy is set at the state level than at the federal level, as explained above. These effects on the different Regimes now go in exactly the opposite direction to those spelt out above. In net terms, welfare falls relative to no lobbying, and there is a bigger reduction in welfare when policy is set at the federal level than at the state level. The overall effect then is that Regime I increases sharply, Regime II stays about the same, Regime III is squeezed, and there still remain a small proportion of Regime IV cases, less than 1\%. (Figure $2 \mathrm{~b}$ shows the indifference curves for No Lobbying and Symmetric Lobbying with net welfare).

So we do get an overturning of Result 5 in Section 3.2 when there is active lobbying: it is now possible to have parameter values for which social pooling is preferred when policy is set at the federal level while political discretion is preferred when policy is set at the state level, implying that harmonisation may be required when policy is moved from the state to federal level. However, these cases are relatively rare. Moreover, as Figure $2 \mathrm{~b}$ makes clear, these cases lie on the borderline between Regime I and Regime II, so the differences in net expected welfare between social and political discretion are very small; whether policy is set at state or federal level, both states are almost indifferent between social polling and political discretion.

We have carried out similar analyses for a wide range of parameter values: ? ? 0.1, 0.3,..,0.9,? ? 0.1, 0.3, 0.5, 1, 10,100 and the same pattern of results obtains. The proportion of cases which lie in Regime IV with active lobbying never exceeds 1\%, and for ? 10 , we get no Regime IV cases. 
We now consider a number of asymmetric cases. For these cases we restrict attention to just two values for ?, 1 and 10, with some groups in some elections facing the lower parameter value and others the higher parameter value. The rationale for these differences in lobbying costs is set out for each of the three asymmetries we model in this paper: democratic deficit, producer bias at federal level and producer bias at state and federal level. In Johal and Ulph (2001b) we also modelled a further asymmetry in lobbying costs: between special interest groups in different states (NorthSouth divide). We have begun modelling the implications of this asymmetry for constitutional choice between social pooling and political discretion, and hope to report on these results in a later version of this paper.

\subsubsection{A 'Democratic Deficit'}

One of the concerns of the anti-globalisation movement is that power has shifted from nation states to unelected bodies such as the WTO, so there is a 'democratic deficit' at this federal level. As noted in Johal and Ulph (2001b), it is difficult to capture this concern in our framework, partly because it is not always clear from the political science literature whether a democratic deficit implies more or less involvement in the decision making process by special interest groups. In this section we model the view that lobbying is part of the democratic process and a 'democratic deficit' arises at the federal level if decisions are taken by 'technocrats' without much scope for influence by different groups in society. So we capture a democratic deficit at the federal level by assuming $? g ? 1, \ldots, 4 ?_{g i} ? 1, i ? 1,2 ; ?_{g F} ? 10$. Thus, all groups face the same costs of lobbying at the state level as in the symmetric lobbying case but now face higher costs of lobbying at the federal level. The results for this case are shown in Columns 4 and 5 of Table 1. Obviously the results when policy are taken at the state level are the same as in the symmetric case, so it is the impact of the change in lobbying costs at the federal level that we need to consider.

Lobbying efforts of all groups in all elections are reduced, slightly at the state level, more markedly at the federal level, so the probabilities of electing environmental governments fall slightly at the state level and more sharply at the federal level, relative to the Symmetric Lobbying case, although the probabilities are still higher than in the No Lobbying Case. Thus the increase in gross welfare when policy is taken is taken at the federal level is positive relative to No Lobbying, but somewhat 
lower than in the Symmetric Lobbying. This means that the upward shift in the federal level indifference curve with gross welfare is slightly less than in the Symmetric Lobbying Case, so Regime I is somewhat bigger than with Symmetric Lobbying, and the squeeze on Regime III is also somewhat greater than with Symmetric Lobbying. The welfare costs of lobbying when policy is set at the federal level are somewhat lower than with the Symmetric Lobbying case $(-1.14 \%$ compared to $-1.21 \%$ ), so on average net welfare is higher than in the symmetric case, though lower than with No Lobbying ${ }^{12}$, increasing Regimes I and III slightly relative to the Symmetric Case.

The results of this way of modelling a democratic deficit are very similar to those of Symmetric Lobbying - so the higher cost of lobbying at the federal level has only very small implications for the choice between social pooling and democratic deficit. Perhaps surprisingly, relative to Symmetric Lobbying, states are slightly more likely to prefer political discretion at the federal level, because the costs of lobbying at the federal level have fallen. As noted in Johal and Ulph (2001b), if we had taken the opposite view of the democratic deficit - that it implies too much lobbying by special interest groups at the federal level - the results would simply have gone in the other direction. But in either case the democratic deficit, as we have modelled it, does not have marked implications relative to the Symmetric Lobbying case.

In Table 1 we have presented results for the case where ? 0.3 , but we get very similar conclusions for all the other values of expected damage costs that we have run.

\subsubsection{Producer Bias - Federal Level}

It can be argued that the real concern of the anti-globalisation movement is not that all interest groups have less influence in bodies like WTO, but that groups like environmental NGOs have much less influence there than groups like TNCs. We capture this concern by assuming that only environmental groups face higher lobbying costs at the federal level, i.e. $? g$ ? $1, \ldots, 4 ?_{g i} ? 1, i$ ? 1,2; but that $?_{g F} ? 10$ for $g$ ? 1,2 and ${ }_{g F} ?$ 1for $g$ ? 3,4. The results for gross and net welfare are shown in Columns 6 and 7 of Table 1.

\footnotetext{
${ }^{12}$ This is only true on average; for very high values of ? and? welfare is higher than with No Lobbying.
} 
As with the Democratic Deficit, the results when policy is set at the state level are exactly the same as with Symmetric Lobbying, and so it is only the impact on results when decisions are taken at the federal level that we need to report. Compared with Symmetric Lobbying, the higher costs of lobbying by environmentalists means that they reduce their lobbying in all elections, slightly in state elections, more markedly in the federal election. Industrialists also reduce their lobbying slightly (strategic complements), and now the probability of electing environmental governments is less than $50 \%$. This means that when policy is set at the federal level, gross welfare now falls relative to No Lobbying. In terms of indifference curves with gross welfare, the federal curve falls slightly, the state curve still rises significantly. So Regime I is still significantly smaller than with No Lobbying but larger than with Symmetric Lobbying, and Regime III again gets significantly squeezed and Regime IV is slightly bigger than with Symmetric Lobbying.

The reduction in lobbying by all groups means that lobbying costs are now only about $1.08 \%$ of welfare when policy is set at the federal level, so despite the fact that gross welfare has fallen, the fall in net welfare, relative to No Lobbying, turns out to be almost exactly the same as with the Democratic Deficit, so not surprisingly the size of the four regimes is almost identical to that with the Democratic Deficit.

So, we get the perhaps rather surprising conclusion that having higher lobbying costs for only environmentalists at the federal level produces outcomes very similar to having higher lobbying costs for all groups at the federal level, at least in terms of the implications for the choice between social pooling and political discretion. Again our results are robust to different values of expected damage costs.

\subsubsection{Producer Bias at State and Federal Levels}

The three cases of active lobbying we have considered so far - Symmetric Lobbying, Democratic Deficit and Producer Bias at Federal Level - have all produced very similar results in terms of the implications for the constitutional choice between social pooling and political discretion at state and federal level. The reason is that the major changes from the No Lobbying case have been determined mainly by what has happened when policy is set at the state level, and this has been the same for all three cases of active lobbying; the differences in lobbying costs at the federal level do 
not have much impact. The next model of active lobbying we consider extends the notion of producer bias by now assuming that environmentalists face higher costs of lobbying than industrialists in all elections. Specifically we assume that $? i, ?_{g i} ? 10, g$ ? 1,2; $?_{g i} ? 1, g$ ? 3,4 . The results for gross and net welfare are shown in columns 8 and 9 of Table 1 .

We begin by explaining what happens when policy is set at the federal level. This is similar to what happened when producer bias was only at the federal level, except that now environmentalists face higher lobbying costs in all elections, and the individual rationality constraints will reflect the different utility levels when policy is set at the state level (as described below). The effect of the higher lobbying cost in all elections is that environmentalists now reduce their lobbying markedly in all elections and the industrialists also cut their lobbying but not by as much. So the probability of electing environmental governments falls sharply at state and federal level, and expected gross welfare falls relative to the No Lobbying case, and by a somewhat greater amount than when producer bias occurred only in federal elections. However, comparing columns 8 and 9, there is now a much smaller cost of lobbying - only $0.7 \%$ of welfare - so that despite the bigger reduction in gross welfare compared with Producer Bias only at the Federal Level, the reduction in net welfare is now much smaller.

The major difference from having producer bias in federal and state elections arises when policy is set at the state level. Again environmentalists substantially reduce their lobbying at state level, and industrialists respond by slightly cutting their lobbying effort. The probability of electing environmental governments falls sharply, to under $40 \%$ in many cases. But the increased probability of having two industrial governments in power, which leads to a lot of strategic competition, means that expected profits fall sharply and expected damage costs rise, and even industrialists are made worse off. So expected gross welfare falls sharply policy is set at the state level. Again the reduction in lobbying means that lobbying costs are now only $1.2 \%$ of welfare, compared to $1.5 \%$ in previous cases we have studied, but combined with the large reduction in gross welfare, net welfare is now substantially lower than in the No Lobbying case.

These effects mean that in terms of both gross and net welfare, the indifference curves between social pooling and political discretion fall when policy is taken at both federal and state level, with the falls being much more pronounced when policy is set at the state level. Compared to the No 
Lobbying case, in terms of gross welfare, Regime I now rises, and Regime II falls sharply reflecting a stronger preference for social pooling. Regime III also expands, since the indifference curves are getting further apart (see Figure 3); but now since the fall in welfare is bigger at the state than federal level, there are no Regime IV cases. In terms of net welfare, the falls in the indifference curves are even bigger, so Regime I gets even bigger, Regime II even smaller; but since the relative falls in welfare are not as marked as with gross welfare, Regime III falls slightly from the No Lobbying Case; but again in terms of net welfare, there are no Regime IV cases.

Thus when we get bigger falls in welfare at the state than at the federal level, Result 5 from section 3.2 is reinforced. Again these results are robust to different values of ?.

\subsubsection{Summary}

When we introduce active lobbying with symmetric lobbying costs, then we have shown that we do get some overturning of the results with No Lobbying, in particular it is now possible for some parameter values to get outcomes in Regime IV where social pooling is preferred to political discretion when policy is set at the federal level, but political discretion is preferred to social pooling when policy is set at the state level. But we do not see this as a serious violation of Result 5 in section 3.2, because these cases are relatively rare, and the differences in expected net welfare between social pooling and political discretion are tiny. Because the major effect on net welfare of introducing active lobbying occurs when policy is set at the state level, introducing asymmetries in lobbying costs when policy is set at the federal level (as we did with Democratic Deficit and Producer Bias at the Federal level) produces results almost identical to Symmetric Lobbying. However when we introduce asymmetries in lobbying costs at the state level, as with Producer Bias at State and Federal levels, we get more pronounced changes in the results relative to Symmetric Lobbying, but this leaves Result 5 unaffected - we get no Regime IV cases.

So our overall conclusion is that Result 5 - our key result on constitutional choice between social pooling and political discretion with No Lobbying - is actually very robust to the introduction of active lobbying, even if there are asymmetries in lobbying behaviour. There are no cases for which there would be a strong preference for social pooling over political discretion when policy is set at 
the federal level and a strong preference for political discretion over social pooling when policy is set at the state level.

\subsection{Policy Set at Federal or State Level?}

The other aspect of constitutional choice we want to explore is whether policy should be set at the state or federal level. As we've already noted, when there is social pooling, there will be no lobbying activity no matter what lobbying costs are, so Result 1 in section 3.2 is unaffected by the possibility of lobbying - with social pooling welfare will always be higher when policy is set at the federal level. So the only question is whether Result 2 in section 3.2 - with political discretion welfare is always higher when policy is set at the federal level - carries over from no lobbying to active lobbying. This is the question we asked in Johal and Ulph (2001b), and, based on numerical simulations, our conclusion was that Result 2 is robust to the introduction of active lobbying, even if there are the kind of asymmetries in lobbying costs modelled in this paper (and Johal and Ulph (2001b) also included the North-South Divide asymmetry). In the numerical simulations we reported in section 4.2 for the choice between social pooling and political discretion we used a much wider range of parameter values than in Johal and Ulph (2001b), and our conclusion remains that for all the kinds of lobbying modelled in section 4.2 we have not found any parameter values for which, with political discretion, it would be better to set policy at the state level rather than the federal level. 


\section{Conclusions}

We have tried, as in Johal and Ulph (2001a, b), to address concerns raised in the anti-globalisation movement that liberalisation of trade and capital markets might lead to a race-to-the-bottom in environmental standards. If this is the case, then to overcome it may require a supra-national body to oversee the setting of environmental standards. This in itself though is problematic. There are concerns that both national governments and supra-national bodies can be captured by special interest groups, particularly TNC's. Furthermore, a supra-national body may be limited in the information it has about damage costs in individual states. To overcome asymmetries of information and the potential political influence of these special interest groups it might then be necessary to adopt what look like rather inefficient policies: e.g. requiring all states to adopt environmental standards as if they faced identical damage costs (equal to the best estimate of what damage costs might be) rather than allowing individual states to fine-tune their policies to what they know about their own damage costs.

In Johal and Ulph (2001a) we set out a model which captured the above concerns: the potential for strategic environmental competition which can be mitigated by having policy set at a supra-national ('federal') level; asymmetries of information about damage costs between agencies (governments) at nation state and supra-national levels, only agencies at the state level learn the true value of their damage costs; agencies at national and supra-national levels can be captured by special interest groups. States then have two 'constitutional choices'. The first is whether to have policy set at the national or supra-national level. Secondly, whether to allow policy to be set by these agencies (with the advantage that state agencies will know true damage costs but with the disadvantage of capture) - what we call political discretion - or to mandate that these agents implement policies based on the only information available at the constitutional stage i.e. maximising welfare based on expected damage costs - what we called social pooling. We showed that it was always better to set policy at the supra-national rather than national levels and that it was never the case that it would be desirable to use social pooling at the supra-national level and political discretion at the state level.

In Johal and Ulph (2001b) we introduced a model of lobbying behaviour in which the probability of capture now depended on the amount of lobbying effort expended by different interest groups. We explored the question of whether with political discretion it remained the case that it was always 
better to set policy at the supra-national level, and concluded that it was, even with quite marked asymmetries in lobbying costs and lobbying behaviour.

In this paper we used the model of lobbying behaviour to test whether the conclusions of Johal and Ulph (2001a) about social pooling and political discretion were robust. We have found that they are in the sense that while there are some parameter values for which it might be desirable to have social pooling at the supra-national level and political discretion at the nation state level, these cases are rare and have very small differences in expected welfare under social pooling and political discretion. So it remains the case that there are no parameter values for which there would be a strong preference for social pooling at the supra-national level and a strong preference for political discretion at the nation state level. We also confirmed the results of Johal and Ulph (2001b) for a wider class of parameter values.

So the use of policies such as harmonisation cannot be rationalised on the grounds that there is now a need to set policy at a supra-national level, and that harmonisation is a way of limiting discretion by agencies that might be captured by special interest groups; if that is true at the supra-national level, it should have been true when policy was set by nation states.

Of course the model used in this paper is very simple, both in terms of the underlying economic model of strategic competition and in the modelling of the political process of capture, and naturally it would be interesting to explore the robustness of our results to richer economic and political models. 


\section{References.}

Boyer, M. and J-J. Laffont (1999) "Toward a Political Theory of the Emergence of Environmental Incentive Regulation”, Rand Journal of Economics, 30, 137-157.

Johal, S. and A. Ulph (2001a) "International Co-ordination of Environmental Policies, Harmonisation and Limiting Political Discretion", University of Southampton.

Johal, S. and A. Ulph (2001b) "Globalisation, Political Lobbying and the Design of International Environmental Governance", Review of International Economics, forthcoming.

Johal, S. and A. Ulph (2001c) "Global Environmental Governance, Political Lobbying and Transboundary Pollution", in J. List and A. de Zeeuw (eds.), Recent Advances In Environmental Economics, forthcoming.

Katz, E. and J. Rosenberg (1989) "Rent-Seeking for Budgetary Allocation: Preliminary Results For 20 Countries”, Public Choice, 60, 133-145

Roemer, J. (1999) “The Democratic Political Economy Of Progressive Income Taxation", Econometrica, Vol. 67 No. 1, January.

Ulph, A. (2000) "Harmonisation And Optimal Environment Policy In A Federal System With Asymmetric Information”, Journal of Environmental Economics and Management, 39, 224-241. 
Figure 1. No Lobbying Case.

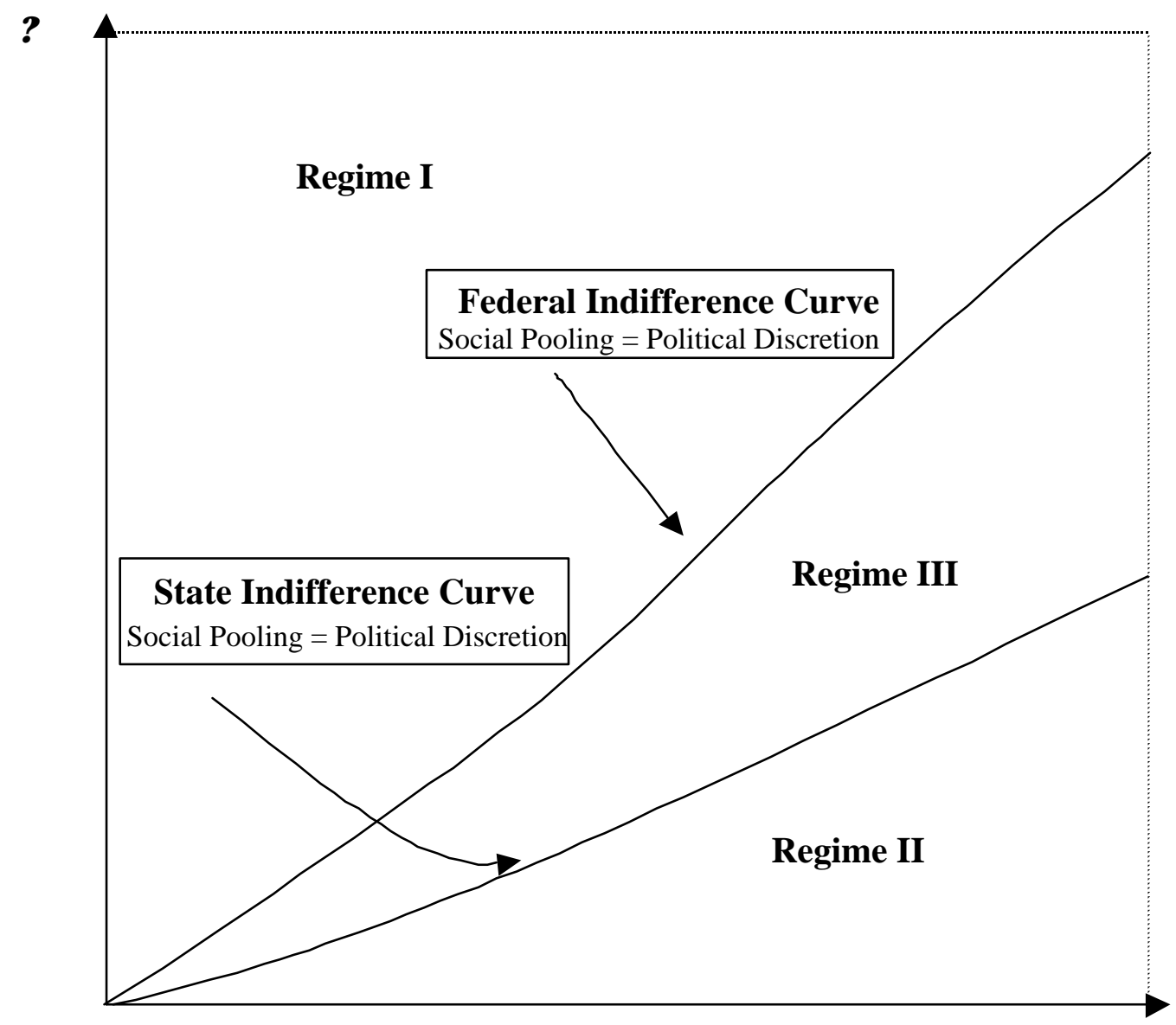


Figure 2a. Gross Welfare For Low Cost Symmetric Case.

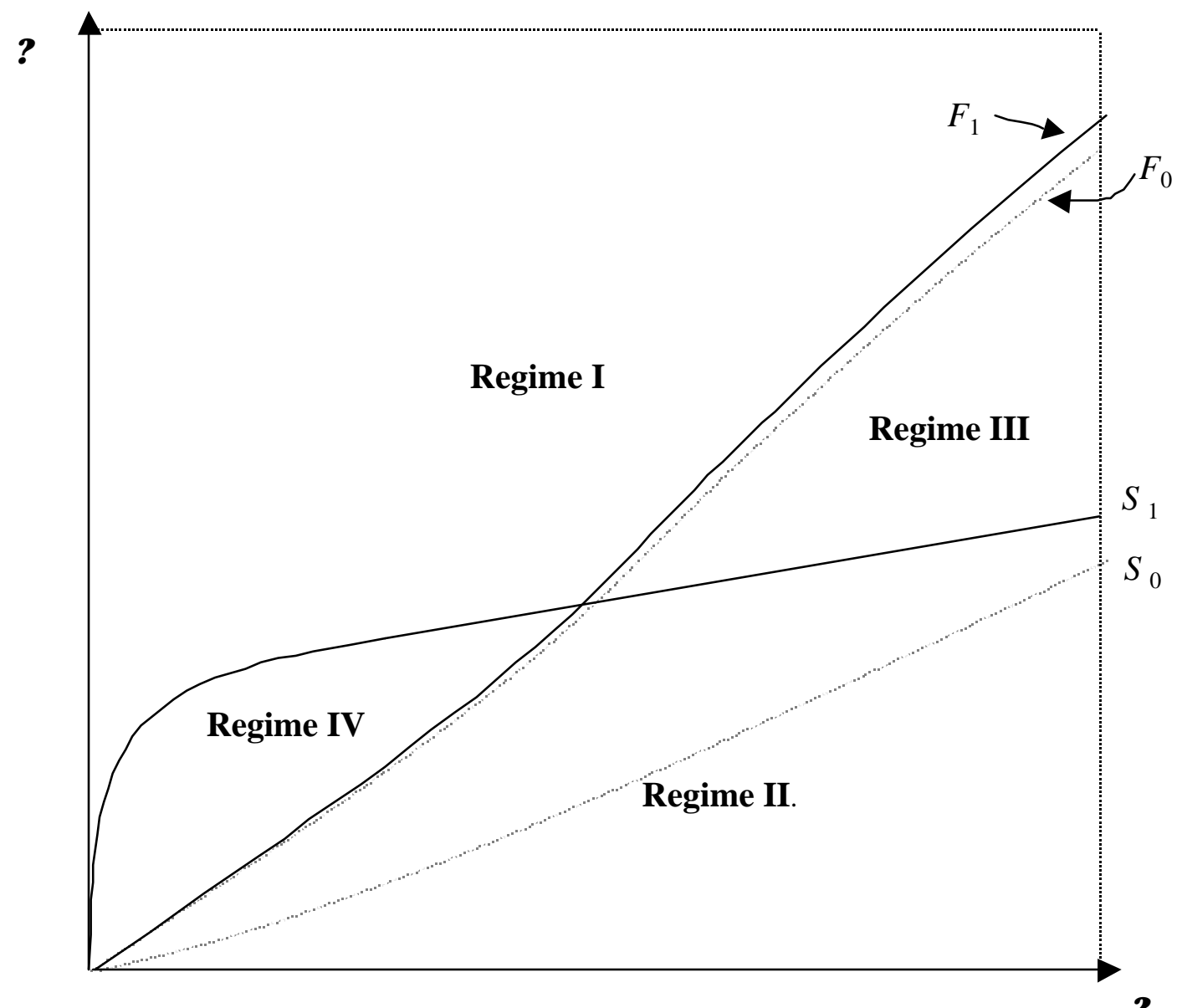


Figure 2b. Net Welfare For Low Cost Symmetric Case.

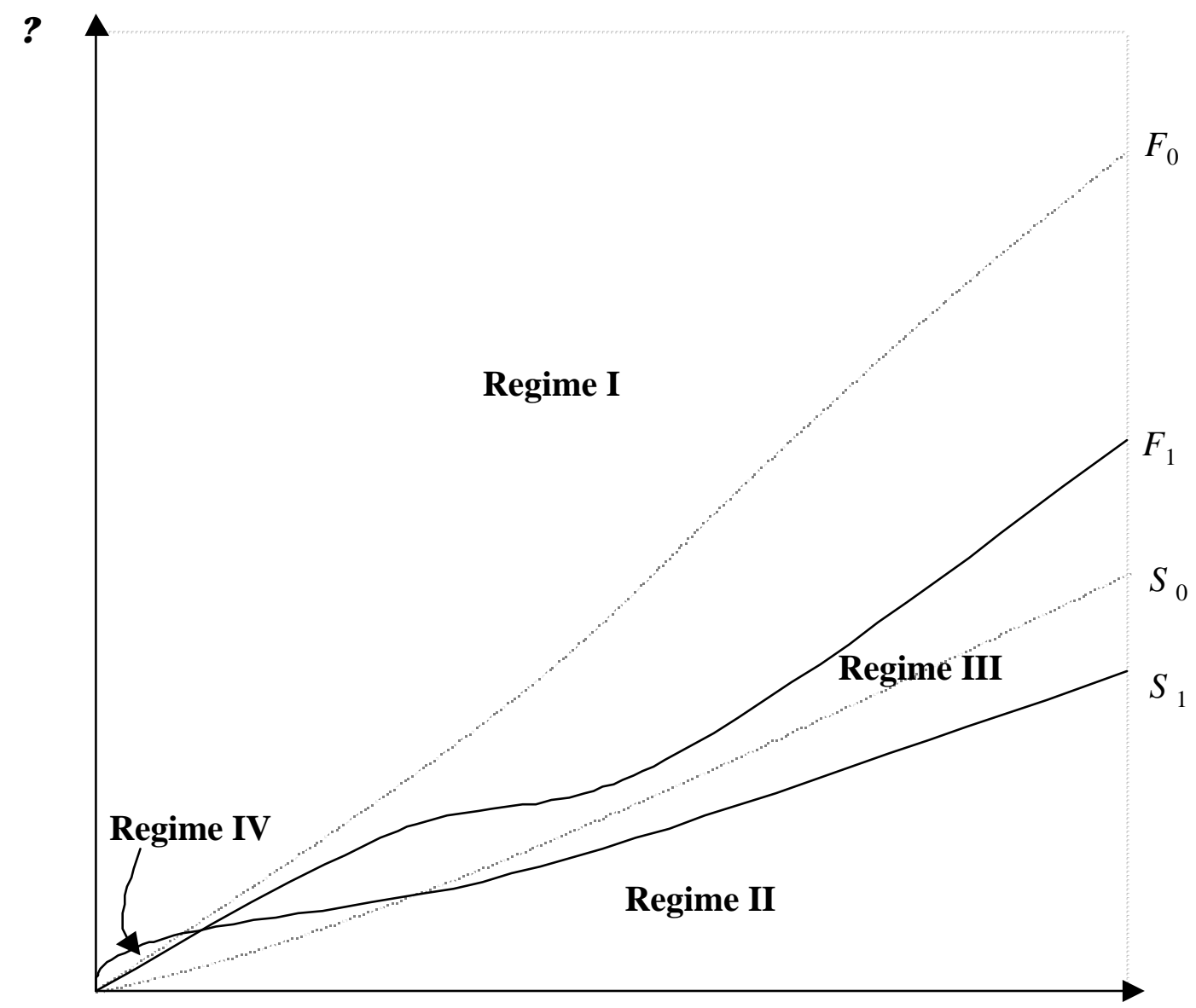


Figure 3. Producer Bias At State And Federal Levels.

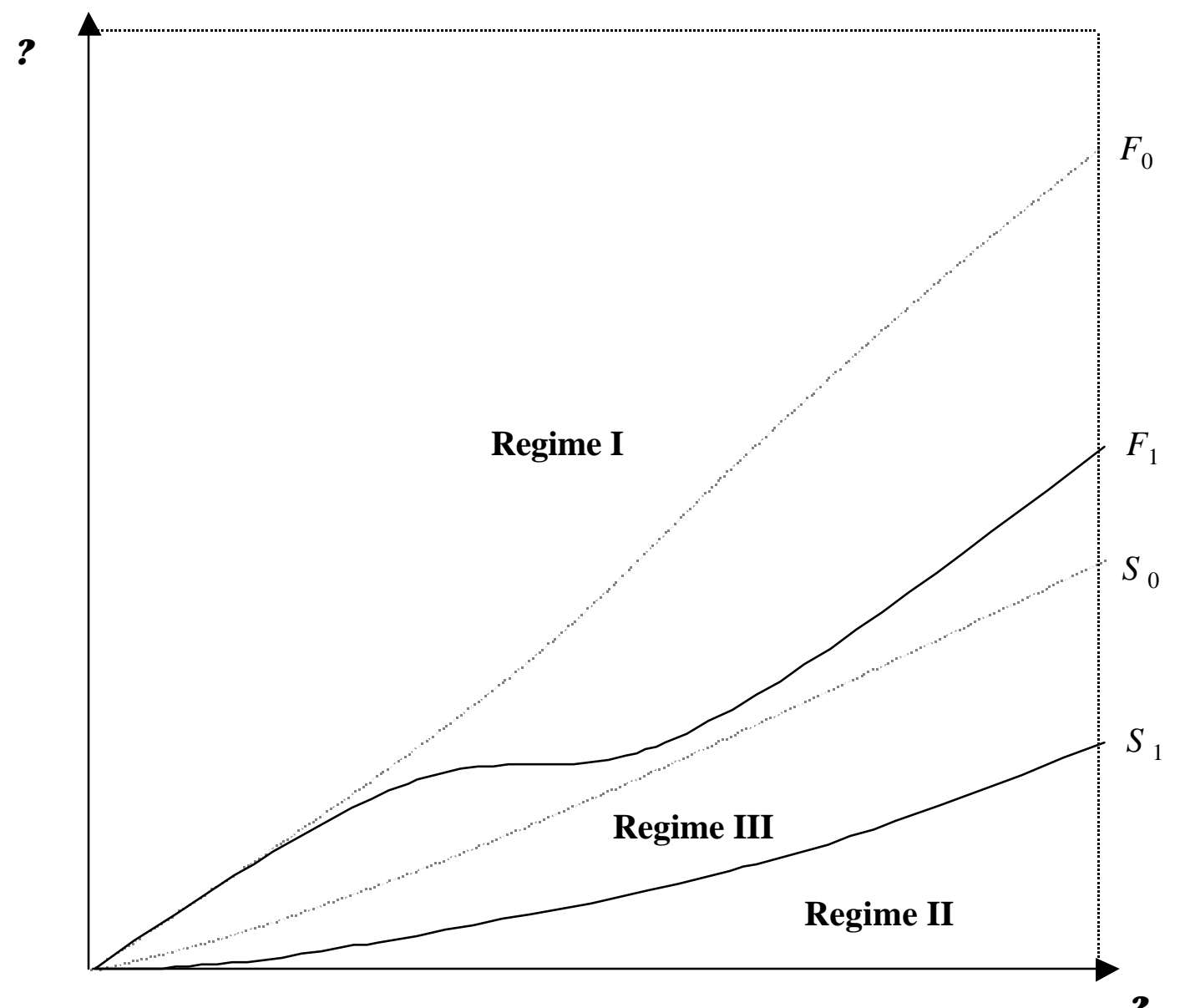


Table 1: Effect of Active Lobbying on Different Regimes (? ? 0.3, ? ? 1)

\begin{tabular}{|c|c|c|c|c|c|c|c|c|c|}
\hline \multirow{3}{*}{$\begin{array}{l}\text { Type of } \\
\text { Lobbying: }\end{array}$} & \multirow{3}{*}{ No Lobbying } & \multicolumn{8}{|c|}{ Active Lobbying } \\
\hline & & \multicolumn{2}{|c|}{ Symmetric } & \multicolumn{2}{|c|}{ Democratic Deficit } & \multicolumn{2}{|c|}{$\begin{array}{c}\text { Producer Bias } \\
\text { Federal Level }\end{array}$} & \multicolumn{2}{|c|}{$\begin{array}{c}\text { Producer Bias } \\
\text { Both Levels }\end{array}$} \\
\hline & & Gross & Net & Gross & Net & Gross & Net & Gross & Net \\
\hline Col. No.: & 1 & 2 & 3 & 4 & 5 & 6 & 7 & 8 & 9 \\
\hline $\begin{array}{c}\% \text { of ? ? ? } \\
\text { space in } \\
\text { Regime: }\end{array}$ & & & & & & & & & \\
\hline $\mathbf{I}$ & 59.8 & 51.7 & 75.6 & 52.0 & 75.1 & 53.2 & 75.2 & 63.3 & 74.2 \\
\hline II & 17.4 & 31.3 & 17.6 & 31.3 & 17.6 & 31.3 & 17.6 & 11.0 & 8.4 \\
\hline III & 22.8 & 9.1 & 6.3 & 8.9 & 6.8 & 7.6 & 6.7 & 25.7 & 17.4 \\
\hline IV & 0.0 & 7.8 & 0.5 & 7.8 & 0.5 & 8.0 & 0.5 & 0.0 & 0.0 \\
\hline $\begin{array}{c}\text { \% Change in } \\
\text { Welfare - } \\
\text { Federal } \\
\end{array}$ & - & 0.02 & -1.19 & 0.01 & -1.13 & -0.06 & -1.14 & -0.08 & -0.78 \\
\hline $\begin{array}{c}\text { \% Change in } \\
\text { Welfare - } \\
\text { State }\end{array}$ & - & 1.18 & -0.35 & 1.18 & -0.35 & 1.18 & -0.35 & -1.45 & -2.65 \\
\hline
\end{tabular}

